\title{
İlköğretim Sanat Etkinlikleri Dersinde Yaratıcı Drama Yönteminin Öğrenci Memnuniyeti Açısından Değerlendirilmesi
}

\author{
Murtaza AYKAÇ.
}

\begin{abstract}
Özet
Bu çalışmada İlkögretim 5.Sinıf Sanat Etkinlikleri dersinin "Müze Kültürü" öğrenme alanına bă̆lı "Tarihte Yaşam Kültürü" temasının ögrretiminde yaratıcı drama yöntemi kullanılarak öğrenci memnuniyeti değerlendirilmiştir. Bu çalışma 2006-2007 öğretim yılında Ankara ili, Keçiören ilçesi, Şehit Mehmet Altanlar İlköğretim Okulu'nda öğrenim gören 5/C sinıfindaki öğrenciler ile sanat etkinlikleri seçmeli dersi kapsamında yürütülmüşür. Çalışma iki aşamada ve ü̧̧ farklı ortamda yürütülmüştür. İlk aşamada uygulama öncesi hazırlıklar yapılmıs, ikinci aşamada ise uygulama çalışmaları yapılmıştır. Çalışma sınıfta 5 saat, Etnografya ve Gordion müzelerinde 11 saat olmak üzere toplam 16 saat yürütülmüştür. Çalışmada veri toplama aracı olarak ögrencilerin görüş ve düşüncelerini belirlemek amacıyla "ögrrenci değerlendirme formu", "yazllan mektuplar" ve "etkinlik değerlendirme formu" kullanılmıştır. Veri toplama araçlarından elde edilen bulgulara göre yaratıcı drama yönteminin ögrencilerin memnuniyeti üzerinde olumlu bir etkisi olduğu söylenebilir.
\end{abstract}

Anahtar Sözcükler: Illköğretim Sanat Etkinlikleri Dersi, müze, yaratıcı drama, ögrenci memnuniyeti

\begin{abstract}
In this study, creative drama teaching method is used and evaluated in the theme 'Culture of Life throughout History' of the course named as Art Facilities, studied by the fifth grade students at primary schools. This study was carried out in the education year 2006- 2007, in Keçiören, Ankara, with the participation of the students studying at 5/C class of Şehit Mehmet Altanlar Primary School within the scope of Art Facilities -optional- Course. The study was carried out in two sessions and three different settings. In the first session, the preparations were made before the implementations and in the second session the implementations occurred. The study took place totally for 16 hours; 5 hours in the classroom and 11hours in the Ethnography and Gordion Museum. In the study, 'student evaluation form', 'facility evaluation form' and 'letters', which are all used in order to determine the students' opinions, were used as means of data gathering tool. It could be supposed that the creative drama techniques have a positive effect on the students' pleasure, depending upon the data gathered by these measuring tools.
\end{abstract}

Keywords: Art Facilities Course, museum, creative drama, students satisfaction 


\section{Giriş}

İnsanın kendini ve çevresini anlama, anlamlandırma ve ifade etme yolculuğunda ona eşlik eden sanat, çağdaş insanın yaşamında da benzer işlevleri yerine getirmektedir. Bu işlevleriyle insan yaşamında önemli bir rol oynayan sanatı, eğitim için de değerli kılmaktadır. Sanat eğitimi, yapıcı ve yaratıcı bir biçimde yetiştirilmesi düşünülen bireyin; insanı, doğayı, yaşamı algılayabilmesini, yorumlayabilmesini ve kendi duygu ve düşüncelerini farklı sanatsal yollarla ifade edebilmesini amaçlamaktadır (MEB, 2006, s.1). Sanatlar eğitiminin en önemli amaçlarından biri öğrencilerin yaratıcıllı̆̆ının geliştirilmesidir. Bu yönüyle bakıldığında sanat eğitimi edilgen, yalnızca verileni alan bireylerden çok yaratıcı düşünebilen olay ve olgular arasında yeni ilişkiler kurabilen bireyler yetiştirilmesine olanak sağlamaktadır. San (2006b)'da sanat eğitimini, “yaratıcı bir süreç olarak algılamakta, bu süreci bir duygu ve zevk eğitimine, güzel biçimlere duyarlık kazanmaya, her türlü anlatım biçiminde estetik yaşantılar yaratmaya yönelik olarak işlev gören, yeni, özgün, çağdaş düşünceler üretmeyi ve yaratıcı bir zihinsel etkinliği gerektirmektedir" biçiminde ifade etmektedir (San, 2006b, s.3). Bu tanımda da görüldüğü gibi sanat eğitimi yaratıcı süreçler gerektirme yanında uygulama sürecinde öğrencilerin yaratıcıllğına olanak sağlayan yaratıcı drama gibi yöntemlere yer verilmesini de zorunlu kılmaktadır.

2006-2007 yılında uygulamaya konulan Sanat Etkinlikleri dersi programı, yaşantılara dayalı, uygulama ağırlıklı, sanatsal verilerden yararlanarak yaratıcı düşünceyi geliştirme amaçlı ve öğrencinin estetik duyarlılığını geliştirici bir yapıda planlanmıştır. Bu yönüyle programda yaratıcı drama, resim, heykel gibi öğrencilerin yaratıcılığını ve hayal gücünü geliştiren alanlara yer verilerek öğrencilerin sanat dallarıyla iletişime girmesi sağlanarak estetik bir duygu oluşmasını, kültürel ve sosyal gelişimine olanak sağlanması amaçlanmıştır.

Öğrencilerin kişilik gelişiminde sanatın önemi yadsınamaz. Özellikle ilköğretim çağında çocukların kişilik gelişiminin önemli bir kısmının geliştiği düşünüldüğünde sanatın ve sanat eğitiminin öğrencilerin toplumsal ve kültürel konulara karşı duyarlılık kazanmalarında önemli bir rolü vardır. Bu yönüyle Güzel Sanatlar Eğitimi ve özellikle yaratıcı drama çalışmalarının öğrencileri ileride yetişkin olarak yer alacakları yaşamdaki rollere, sorumluluklara ve deneyimlere hazırlaması, öğrencilerin okul ve toplum içinde bilişsel, duyuşsal ve estetik yaratıcılığını geliştirmesi açısından önemlidir.

\section{Sanat Etkinlikleri Dersi ve Yaratıcı Drama}

Son yıllarda ülkemizde öğrenciyi merkeze alan öğretmenin rehber olabileceği aktif öğretim yöntemlerinin kullanılması yönünde bir eğilim olduğu gözlenmektedir. Bu yöntemlerden biri olan yaratıcı drama yöntemi gerek uygulama biçimi gerekse yaratıcı dramanın kendi içinde barındırdığı 
özellikleri ile öğrenciyi etkin kılan bir yöntem olarak öğrenim sürecinde işlevsel olarak kullanılmaktadır. Eğitimde bir yöntem, bir sanat alanı ve bir disiplin olarak üç boyutu olan yaratıcı drama, eğitimöğretimde herhangi bir konuyu, doğaçlama, rol oynama gibi tekniklerinden yararlanarak, bir grupla ve grup üyelerinin birikimlerinden, yaşantılarından yola çıkarak canlandırmalar yapmaktır, biçiminde tanımlanmaktadır (Adıgüzel, 2006, s.21).

Sanat eğitimi sürecinde çocuk sanatsal yaratıcı etkinlik içindedir. Yaratıcılığın kapsadığı duygusal ve düşünsel basamaklardan geçer. Tekniğin imkânları ile malzemenin dilini kullanır, tasarlar, çözümler, biçimlendirir, eleştirir, değerlendirir. Bu süreci bir grubun içinde yaşadığında, diğerleriyle iletişime girer, etkileşir. Sanatın özüne, ilke ve ögelerine ilişkin sözel iletişim kurar. Bu etkileşim, eğitim ortamını zenginleştirir ve bu eğitsel yaşantıyı paylaşanların gelişimine katkıda bulunur. İnsanın estetik duyarlılık kazanması sürecinde birikimine katkı sağlamaktadır (Kurtuluş, 2006, s.46). İlköğretim okullarına sanat eğitimi süreçlerinde içinde barındıran sanat etkinlikleri gibi öğrencilerin sosyal kültürel gelişimlerine olanak sağlayabilecek bir dersin konulması kuşkusuz yukarıda belirtilen unsurların gerçekleştirilmesi açısından çok önemlidir. Ancak sanatsal etkinliklerini yalnızca 80 dakikalık bir dersle sınırlandırmanın yeterli olmayacağı açıktır. Bu anlamda tüm derslerin ve öğrenim alanlarının sanatsal etkinliklerle örülmesi, öğrencilerin yaratıcı ve düşünen birer birey olarak yetişmeleri için oldukça önemlidir. Fakat sanatsal etkinlikler sadece derslerle de sınırlı tutulamaz. Ders dışındaki zamanlarını sosyal ve kültürel etkinlikler içinde geçiren öğrencilerin sanatsal ürünleri paylaşması ve yeniden üretmesi daha işlevsel olabilecektir. Bu yönüyle okullardaki eğitsel kol faaliyetleri, kulüp faaliyetleri, geziler, halk oyunları, tiyatro, resim ve heykel gibi çalışmalar öğrencilerin kişilik geliş̧imlerinde önemli bir işlev üstlenebilecektir.

Yapılandırmacı yaklaşıma uygun olarak hazırlanarak uygulamaya konulan yeni eğitim programı ile birlikte ilköğretim programına dâhil edilen Sanat Etkinlikleri dersi öğrencilerin eğitimi açısından önemli bir işlev yüklenebilecektir. Sanat Etkinlikleri dersi, özellikle ilköğretimin ilk kademesinde, ana kaynak malzemesi, öğrencinin yaşam alanıdır; çocuğun özellikle 10. yaşına değin, kavram ve düşünce formlarını kullanmamasına çalışılıp, nesne ve olayların içgörüsel formlarının aktarılması, böylece çocukların imgelerin açıklanıp çoğaltılmasını ve aynı zamanda çocuğun bedensel ve zihinsel işlevlerinin eğitilmesini amaçlamaktadır (San, 2006a, s.16). Bu ders programının önemini artıran diğer önemli iki unsursa programın ve programa ilişkin olarak hazırlanan etkinliklerin, drama ve tiyatro alanından uzmanlarca hazırlanması ve sanatsal etkinliklerin yaratıcı drama gibi öğrencilerin yaratıcıllğını geliştiren yöntemlere dayalı olarak hazırlanmasıdır. Öğrenciler bu derste yaratıcı drama yöntemi ile yaşam ve yaşamsal olgu ve olayları içeren sanatsal ürünlerle ilgili rol oynama, doğaçlamalar yaparak sanatsal bir duyarlılık ve estetik kazanma yanında, yaratıcı sanatsal ürünler oluşturabilecektir. 
Özellikle diğer derslerle iletişimde, öğrenciye ve öğretmene yeni bakış açıları kazandırmada, işbirliği yapmada sanat eğitimi katalizör bir rol üstlenebilecektir. Bu konuda sanat eğitiminde yeni yöntemler vardır. Bu yöntemlerden birisi de yaratıcı drama yöntemidir (Çakır-İlhan, 2006b, s.419).

Yaratıcı drama aynı zamanda bir sanat eğitimidir. Çünkü Güzel Sanatlar Eğitiminin bütün çalışma alanlarının amaç, ilke ve kapsamlarını içerebilmektedir. Ayrıca yaratıcı drama, yaratıcılığı geliştiren bir eğitim yöntemi ve yaratıcı bireyi yetiştiren başlı başına bir alandır.

Yaratıcı drama eğitim ve öğretimde yeni bir oluşumdur. Ezbere ve bilgi yığmacasına dayalı bir eğitim dizgesinde birey, çeşitli uyguların yaptırımlarından kurtulamamakta, bilgiyi arayarak, paylaşarak, yaşayarak bulamamaktadır. İşte bu nedenle yaratıcı drama bir eğitim dizgesi için önemli bir gereksinmedir (Adıgüzel, 1995, s.4). Yaratıcı drama aynı zamanda yaratıcılığı geliştiren etkili bir yöntem, yaratıcı bireyi yetiştiren başlı başına bir eğitim alanıdır.

\section{Müze ve Yaratıcı Drama}

Müzeler genellikle eski eserlerin korunduğu saklandığ1 yer olarak algılanmakla beraber müzelerin asıl işlevi geçmişle gelecek arasında bağlar kuran etkileşimli bir eğitim ortamı olmalarıdır. Bu yönüyle bakıldığında müzeler bir yandan toplumların bilim ve sanat ürünlerinin sergilendiği, düne, bugüne ve geleceğe 1şık tutan yerler olarak işlev görürken diğer yandan bireylerin geçmişi ile canlı etkileşim kurduğu görsel unsurları ağırlık taşıyan, tüm duyuları harekete geçiren etkili bir eğitim ortamına dönüştürülebilir.

Müzeler "toplum ve onun gelişiminin hizmetinde, halka açık, insana ve yaşadığ 1 çevreye tanıklık eden malzemeleri araştıran, toplayan, koruyan, bilgiyi paylaşan ve sonuçta inceleme, eğitim ve zevk alma doğrultusunda sergileyen kar amacı gütmeyen ve sürekliliği olan bir kurum” olarak tanımlanmaktadır. Amaç topluma ve onun gelişimine hizmetse, çizginin bir ucunda birey ve toplum, diğer ucunda ise insana ve yaşadığı çevreye tanıklık eden malzemelerin bulunması, müzeleri bu iki grup arasında ilişkiyi kuran, iletişimi sağlayan kurumlar olarak önemli bir konuma getirmiştir. Müze, toplayan, araştıran, belgeleyen, bilgi toplayan, koruyan, depolayan, sergileyen ve eğitim veren bir kurum olarak insanın geçmişten günümüze olan tüm gelişimini nesnelerle topluma iletirken, birçok bilim dalından da yararlanmaktadır (Atagök, 2006, s.59). Müze kültürünün gelişmesinde, müzelerin bir eğitim ortamı olarak kullanılmasının önemli bir yeri vardır.

Müze kültürüne ilişkin çalışmalar müzelerde yapılabileceği gibi, müze ortamı haline getirilen sınıf ya da okulun başka bir yerinde de yapılabilir. Örneğin öğrencilerin yaşadığı yerde bir heykel müzesi yoksa sınıfın duvarlarına heykel müzelerinde yer alan nesnelerin fotoğrafları asılarak ya da öğrenciler 
tarafından yapılan heykellerle (bedenleri ile veya kil, seramik hamuru gibi malzemelerle) aynı çalışma yapılabilir.

Müzedeki öğrenme, okulöncesi, ilköğretim ya da yükseköğretim gibi belirli öğrenim kademeleri ile sınırlı değil, tüm yaşam boyu devam edebilir. Çünkü müze bir insanın her yaş döneminde ona ‘tüketebileceği' olanakları sunar. Belli bir belgeyi ya da not almayı gerektirmediği ve katılımda çoğu zaman gönüllülük esas olduğu için geleneksel okulun dışında geniş bir mekânda katılımcılarına ya da ziyaretçilerine özgür bir öğrenme ortamı sunar. Beş duyuyu kullanarak, keşfederek, araştırarak, bizzat uygulamalara katılarak daha etkili ve kalıcı yaşantılar elde edebilirler. Bu özellikleri nedeniyle müze pedagojisi; müzeden hareketle ve müze yoluyla öğretmek olarak da tanımlanabilir (Adıgüzel, 2001, s.27).

Son yıllarda eğitim bilimleri ile müzecilik arasında önemli bir yakınlaşma sağlanması müze pedagojisi (eğitimi) anlayışını ortaya çıkarmıştır. Müzecilik artık nesnelerin sadece sergilendiği bir mekân değil, sürekli yaşayan canlı ve ziyaretçileri ile objeler arasında birebir iletişim kurma çalışmalarının yoğunlaştığı bir anlayışa yönelmesine yol açmıştır. Eğitim bilimleri, öğrenmenin yalnızca okulla sınırla olmadığı ve farklı mekânları kullanmanın eğitimde daha etkili ve kalıcı sonuçlar verdiği yönünde gelişmektedir (San ve Adıgüzel, 2001, s.30). Bu yönüyle bakıldığında müzelerde yapılacak sanat ve kültür eğitiminin amacı, müzeleri eğitim alanı olarak kullanırken, klasik gezme yerine (müzenin belli bir sıra ile yalnızca görerek gezilmesi durumu) öğrenciyi oradaki nesnelerle bütünleştiren, yaparak yaşayarak öğrenmeye olanak sağlayan yöntemlerle müzelerin aktif olarak gezilmesi, interaktif öğretim ortamlarının oluşmasına katkı sunacaktır. Bu etkin ortamı sağlayacak yöntemlerden biri olan yaratıcı drama yöntemi ile müzelerin gezilmesi müzelere karşı duyarlılığ geçirerek kalıcı bir öğrenmeyi de sağlayabilecektir.

Özellikle bir eğitim ortamı olarak müzelerden yararlanmak, müzelerdeki eserlerden hareketle doğaçlamalar oluşturmak, o eserleri tanımaya çalışmak dramanın sanatla, tarihle buluştuğu en önemli çalışmalardan biri olacaktır (Çakır-İlhan, 2006a, s.75). Bu açıdan değerlendirildiğinde içerisinde yaratıcı unsurlar taşıyan yaratıcı drama, öğrencilerin sanatsal ve tarihsel ögelere karşı duyarlılık kazanması yanında sanatın ve kültürün gelişimine de önemli katkılar sunabilecek bir yöntem olarak işlev görebilecektir.

Müzeler, tarihsel, müzecilik ve eğitimsel işlevlerinin yanında başlı başına bir öğrenme ortamı olarak değerlendirilebilir. Müzelerin sahip olduğu içerik eğitim açısından yerinde bir eğitim anlayışına yönelik olarak önemli bir firsattır. Bu gerekçeye dayalı olarak müzenin temel işlevlerinden birinin eğitim olduğu görülmektedir. $\mathrm{Bu}$ eğitim ister doğrudan bilime ve bilgiye, ister duygu ve sezgilere yönelsin, bireye kattı̆̆1 yaşantısal zenginliklerle ona yeni ufuklar açar, bilişsel ve duyuşsal açıdan onu donatır, daha 
yaratıcı bir yaşama yöneltir. Bireye gerekli tarih bilinci ve çevre bilinci verir. $\mathrm{Bu}$ nedenle müzeler bilgisel öğrenmenin yanı sıra, duyuşsal ve yaşantısal öğrenmenin de sağlayacağı bir ortam olarak değerlendirilebilir (Adıgüzel, 2002, s.2). Bu yönüyle yaratıcı dramanın sanat etkinlikleri dersinde kullanılması Sanat Etkinlikleri dersi programının genel amacı olarak ifade edilen "yaratıcı drama ve tiyatro yöntemini kullanıp bütün sanat alanlarından yararlanarak öğrencinin yapıcı ve yaratıcı bir birey olarak yetişmesine destek olmaktır" amacının gerçekleştirilmesinde önemli bir rol üstlenebilecektir. Aynı şekilde farklı öğrenme ortamlarından biri olarak tanımlayabileceğimiz müzelerin yaratıcı drama yöntemiyle etkin bir biçimde kullanılması sanat etkinlikleri dersinin işlevsel olmasında önemli katkılar sağlayabilecektir.

\section{Çalışmanın Önemi}

Bu çalışma ilköğretimde 2006-2007 yılında uygulamaya konulan program içerisinde yer alan Sanat Etkinlikleri dersi programı içerisindeki “Müze Kültürü” öğrenme alanına bağlı “Tarihte Yaşam Kültürü” temasının yaratıcı drama yöntemiyle uygulanmasına dönük bir çalışmadır. Çalışma iki açıdan öneme sahiptir. Birincisi Sanat Etkinlikleri dersinin değerlendirilmesine yönelik olarak yapılan ilk çalışmalardan birisi olmasıdır. İkincisi ise öğrenci merkezli ve öğrencilerin yaşantılarına dayalı bir içerikle hazırlanan bir derstir. $\mathrm{Bu}$ açıdan değerlendirildiğinde, uygulama sürecinde tiyatro ve yaratıcı drama gibi aktif yöntemlere yer veren, bünyesinde resim, heykel, müzik gibi farklı sanat alanlarını barındıran, öğrenme alanı olarak ise sadece sınıfı değil, müze, sanat galerileri gibi farklı eğitim ortamlarına yer veren Sanat Etkinlikleri dersi, ilköğretim için önemli bir yere sahip olacaktır. Bu yönüyle bu ders öğrencilerin yaratıcılığını, hayal gücünü geliştirmeyi ve sanat eserlerine bakışlarını değiştirmelerine olanak sağlayacak şekilde planlanmış ve yaratıcı drama yöntemiyle etkili bir öğrenme sürecine dönüştürülebilme özelliğine sahiptir. Derse yönelik, öğrencilerin motivasyonu ve memnuniyeti üzerindeki etkinin ne olduğunun belirlenmesi ve etkili bir öğrenme süreci, sanat etkinliklerinin geliştirilmesi açısından önemlidir.

Öğrencilerin kişilik gelişiminin önemli bir kısmının ilköğretim çağında olduğu düşünüldüğünde birçok sanat dalını içerisinde barındıran Sanat Etkinlikleri dersinin gerek var olan içeriği gerekse öğrenmeöğretme sürecinde uygulanan yöntemlerin etkililiği açısından bu gelişime önemli katkılar sunabileceği düşünülmektedir.

Sanat Etkinlikleri dersinde ağırlıklı olarak yaratıcı drama yönteminin kullanıldığı görülmektedir, Yaratıcı drama süreç odaklı olduğu ve üründen daha çok süreci göz önünde bulundurduğu için bu dersin öğrencilerin, demokratik, bağımsız düşünebilmesinde, hoşgörülü ve yaratıcı bireyler olarak yetişmelerinde ve toplumsal bir kimlik kazanmalarında önemli bir işlevi olabilecektir. Ayrıca bu çalışma 
kapsamında hazırlanan yaratıcı drama etkinliklerinin bu dersin öğretmenlerine yol göstereceği ve öğrencilerin öğrenmesine de önemli katkılar getireceği düşünülmektedir.

\section{Çalışmanın Amacı}

Bu çalışmanın amacı, İlköğretim birinci aşama düzeyinde 5.Sınıf Sanat Etkinlikleri dersi, Tarihte Yaşam Kültürü temalı, Müze Kültürü öğrenme alanının yaratıcı drama yöntemiyle işlenmesinin, öğrenci memnuniyeti açısından değerlendirilmesidir.

\section{Çalışma Grubu}

Çalışma grubunu 2006-2007 öğretim yılında Ankara ili, Keçiören ilçesi, Şehit Mehmet Altanlar İlköğretim Okulu’nda öğrenim gören 5/C sınıfındaki öğrenciler oluşturmaktadır. Çalışmanın uygulandığı öğrenci grubu, 11-12 yaş grubudur; öğrencilerin 13'ü kız, 14'ü erkek, toplam öğrenci sayıs1 27 'dir.

\section{Çalışmada Kullanılan Yöntem ve Teknikler}

Çalışma uygulanırken yaratıcı drama yöntemi ve yaratıcı drama tekniklerinden; rol oynama, doğaçlama, donuk imge, fotoğraf anı teknikleri kullanılmıştır.

\section{Çalışmada Kullanılan Veri Toplama Araçları}

Çalışmada 4 açık uçlu sorudan oluşan öğrenci değerlendirme formu ve 5 açık uçlu sorudan oluşan "etkinlik değerlendirme formu" hazırlanarak veri toplama aracı olarak kullanılmıştır. Ayrıca öğrencilerin Gordion Müzesinde yaşadıklarıyla ilgili duygu ve düşüncelerini anlatan "mektuplar" da veri toplama aracı olarak değerlendirilmiştir. Öğrenci değerlendirme formunda öğrenci memnuniyetini belirlemek amacıyla "Öğrenme sürecinde mutlu oldunuz mu neden? Müzedeki çalışmalar sırasında hangi duyguları yaşadınız? Yaratıcı drama yöntemiyle daha iyi öğrendiğinizi düşünüyor musunuz? Niçin? Diğer derslerde yaratıcı drama yönteminin uygulanmasını ister misiniz? Neden?” soruları yer almıştır. Etkinlik değerlendirme formu yarı yapılandırılarak "Bu etkinlikte.....duyguları hissettim, bu etkinliğin en hoşlandığım yerleri....., bu müzeyi arkadaşlarıma öneririm çünkü.....” gibi ifadelerde öğrencilerin duygularını belirtmeleri istenmiştir. Bu şekliyle hazırlanan veri toplama araçlarına ilişkin olarak Türkçe, Ölçme Değerlendirme, Program Geliştirme uzmanlarının görüş ve önerileri doğrultusunda gerekli düzeltmeler yapılarak ölçeğe son şekli verilmiştir. Bu haliyle hazırlanan ölçekler deneme amaciyla Türkkent İlköğretim Okulu 4 sınıfta öğrenim gören 20 öğrenciye uygulanmıştır. Uygulama sonucunda ölçekteki ifadelerin anlaşılır olduğu ve araştırmanın amaçları açısından uygun olduğu görülerek araştırmada veri toplama aracı olarak kullanılmıştır. Bu araçlardan elde edilen öğrenci görüş ve düşünceleri gruplandırılarak yorumlanmış ve aşağıda belirtilen sonuçlara ulaşılmıştır. 


\section{Sonuç ve Öneriler}

Öğrenciler, yaratıcı drama ile grup çalışmalarında her şeyi paylaşarak yaptıklarını, canlandırma yaparak, oyun oynayarak, derslerin eğlendirici ve akıcı geçmesini sağladığını ve yaratıcı drama yöntemiyle ders işlemenin kendilerini mutlu ettiğini belirtmişlerdir. Ayrıca öğrenciler derslerde sürekli olarak doğaçlama ve canlandırmalar yaparak, afiş hazırlayarak ve resim yaparak tarihteki yaşam kültürünün günümüz kültürüyle ilişkisi olup olmadığını yaşayarak öğrendikleri için yaratıcı drama ile işlenen, tarihte yaşam kültürü temasını daha iyi öğrendiklerini ve bilgilerinin daha kalıcı olduğunu ifade etmişlerdir.

Öğrenciler, daha öncede müzelere gittiklerini ama bu kez oyun oynayıp canlandırmalar yaptıkları için öğrenme ortamındaki etkinliklere büyük bir heyecanla ve istekle katılarak öğrenme sürecinden mutlu olduklarını ifade etmişlerdir. Öğrencilerin uygulamanın yapıldığı Perşembe günleri okula büyük bir heyecanla geldiklerini belirtmeleri de öğrencilerin öğrenme sürecindeki motivasyonunu gösteren ve öğrenmeyi olumlu yönde etkileyen bir süreç olarak görülebilir.

Öğrenci mektuplarındaki ifadeler öğrencilerin yaratıcı drama yöntemiyle müze çalışmasında oldukça mutlu olduklarını göstermektedir “Gordion Müzesine geldiğim için çok mutluyum. Müzeyi ve Midas'ın mezarını ve canlandırmaları çok beğendim." (G.G.), "Müzenin bahçesinde güzel bir oyun oynadık, eşimle birlikte müzeyi gezdik. Gordion Müzesini çok sevdim. Milattan önce insanların kullandığı araç ve gereçlerin neler olduğunu öğrendim.” (G.A.), “Arkadaşlarımızla grup oluşturduk. Öğretmenimiz bizden en sevdiğimiz nesneyi seçmemizi istedi. Biz müzede bulunan iskeleti seçtik ve bir öykü yazıp onu canlandırdık. Bu pazar hem eğlendik hem de çok şey öğrendik.” (F.Ş.).

$\mathrm{Bu}$ sonuçlar dikkate alındığında genel olarak yaratıcı drama yönteminin öğrencilerin derse karşı gerek motivasyonu gerekse öğrenci memnuniyeti üzerinde önemli sayılabilecek etkileri olduğu söylenebilir. Yaratıcı drama, öğrenimi sıkıcı, durgun, ilgi uyandırmayan ve çekici olmayan bir sınıf ortamından kurtararak, müze ve sergilerle bütünleştirmiş, öğrenim sürecini öğrenciler için eğlenceli, ilgi uyandırıcı, katılımcı ve etkili bir eğitsel bir ortama dönüştürmüş̧ür. $\mathrm{Bu}$ açıdan değerlendirildiğinde bu ortam öğrenciler için hem zevkli hem de onların öğrenmelerinin kalıcı olmasına olanak sağlamıştır. İlköğretimde yer alan sanat etkinlikleri dersi amacına ve içeriğine uygun şekilde yaratıcı drama gibi aktif öğretim yöntemlerin etkili bir şekilde kullanılmasıyla, öğrencilerin gerek öğrenmesi üzerinde gerekse sosyal, kültürel ve kişilik gelişimleri üzerinde oldukça önemli bir işlev görecek gibi görünmektedir. Elbette bunda, bu dersin içeriğinde birçok sanat dalı ve sanatsal ürünün yer almasının yanında, uygulama sürecinin öğrenci yaşantılarına dayalı olarak planlanıp yaratıcı drama gibi aktif öğretim yöntemleriyle birlikte işlenmesinin de önemli bir rolü olduğunu söylemek mümkündür. 
Uygulama sonuçları genel olarak değerlendirildiğinde, yaratıcı drama uygulamaları ile müzeye dönüştürülen sınıf ortamının ve bir öğrenme mekânı olan müzelerin, öğrenci motivasyonu, öğrenmenin kalıcılığ1 ve öğrencinin mutluluğu üzerinde önemli bir etki yarattığı söylenebilir. Bu yönüyle okullar, dersten kaçılan, zil çaldığında hızla uzaklaşılan bir mekândan çok, öğrencilerin ilgi ve merakını uyandıran, öğrenirken heyecan ve mutluluk duyulan bir çekim merkezine dönüşebilmektedir. Aynı olgu müzeler için de geçerli kılınmakta, müze ve sergiler yaratıcı drama gibi etkili yöntemlerle, kısa sürede gezilen ve yalnızca belli objelerin bulunduğu bir görüntüden kurtarılarak, toplumların, kültürel, sanatsal ve tarihsel üretimlerinin paylaşıldı $\breve{g}$, kültürel öğelerin ve tarihsel değerlerin yaşatıldığı, etkili bir eğitim ortamına dönüştürülebilmektedir. Bu sonuçlar ışığında yaratıcı drama yönteminin etkili olması ve müze eğitiminin işlevselliği açısından aşağıdaki önerilerde bulunulmuştur.

1. Okullarda Sanat Etkinlikleri derslerinde bir aktif öğrenme yöntemi olarak yaratıcı dramanın kullanımı arttırılmalıdır.

2. Okullarda yaratıcı drama yönteminin etkili bir şekilde uygulanabilmesi için çalışmaya elverişli fiziki ortam düzenlemeleri yapılmalıdır.

3. Öğretmen yetiştiren eğitim fakültelerinde seçmeli ders olarak yer alan Müze Eğitimi zorunlu hale getirilmelidir.

4. Müzeler, gerek görsel gerekse fiziki mekân açısından daha işlevsel kılınmalıdır.

5. Öğretmen ve öğrencilerin müzelere ulaşımı kolaylıkla sağlanmalı, bürokratik engeller ve işlemler (prosedürler) azaltılmalıdır.

\section{Kaynaklar}

Adıgüzel, H. Ö. (1995). Yaratıı Drama. Çağdaş Yaşamı Destekleme Derneği Beşiktaş Şubesi Sempozyumu, İstanbul, 17-18 Haziran.

Adıgüzel, H. Ö. (2001). Bir Öğrenme Ortamı Olarak Müzelerin Sosyal Bilgiler Ö̈̆retiminde Kullanımı. Eyüpoğlu Eğitim Kurumu Yayınları, 25-29.

Adıgüzel, H.Ö. (2002). Eğitsel ve Sanatsal Etken Olarak Müzeler, Müze Pedagojisi ve Toplum İlişkisi. 5. Uluslararası Sempozyum ve Sanat Etkinlikleri, ODTÜ ve SANART Estetik ve Görsel Kültür Derneği, 1-3 Mayıs.

Adıgüzel, H.Ö. (2006).Yaratıcı drama kavramı, bileşenleri ve aşamaları. Yaratıcı Drama Dergisi, 1(1), $17-29$. 
Atagök, T. (2006). Müze Eğitimbilimi ve Sanatlar. Sanat Eğitiminde Sanat Biliminin Rolü, Naturel Yayınları. Ankara.

Çakır-İlhan, A. (2006a). Tiyatro / Drama Eğitimbiliminde Plastik Sanatların Rolü. Sanat Eğitiminde Sanat Biliminin Rolü, Naturel Yayınları. Ankara.

Çakır-İlhan A. (2006b). İlköğretimde Sanat Eğitimi ve Eğitsel Yaratıcı Drama Yaratıcı Drama 19851998 Yazılar. (Ed. H. Ömer Adı̈üzel). Ankara: Naturel Yayınları.

Kurtuluş, Y. (2006). Sanat Bilimi ve Sanat Eğitimi Uygulamaları. Sanat Eğitiminde Sanat Biliminin Rolü, Naturel Yayınları. Ankara.

MEB (2006). İlköğretim Sanat Etkinlikleri Dersi Programı ve Kılavuzu. Devlet Kitapları Müdürlüğü. Ankara.

San, İ. ve Adıgüzel, H.Ö. (2001). Eğitim sürecinde zekâ ve yaratıcı düşünme çalıştayı. Eğitim Dergisi. Y1l: 2, Sayı: 22, Mili Eğitim Basımevi, Ankara.

San, İ. (2006a). Sanatlar İle Bilim-Kuram İlişkisi. Sanat Eğitiminde Sanat Biliminin Rolü, Naturel Yayınları. Ankara.

San, İ. (2006b). Sanat ve Yaratıcılık Eğitimi Olarak Tiyatro. Yaratıcı Drama 1985-1998 Yazılar. (Ed. H. Ömer Adıgüzel). Ankara: Naturel Yayınları. 


\section{EK 1: Sanat Etkinlikleri Dersinin “Müze Kültürü”ne bağlı “Tarihte Yaşam Kültürü” Temasını Konu Alan} Oturumların İçeriği

\section{Oturum}

Ders: Sanat Etkinlikleri Dersi

Sinıf: 5-C

Süre: $40+40=80$ dakika (ders saati)

Tarih: 26.04.2007

Öğrenme Alanı: Müze Kültürü

Tema: Tarihte Yaşam Kültürü

Kazanım: Yaşam kültürlerini farklı sanatsal yollarla ifade eder.

Yöntem ve Teknikler: Yaratıcı drama, rol oynama, doğaçlama

Araç-Gereç: 25 adet Antalya Kum Heykel Sergisinin 25 adet fotoğrafı, 25 adet A4 kâğıdı, 25 adet kurşun kalem, 30 kg'lık seramik çamuru, CD Çalar, Helena Paparizou, My Number One.

\section{Hazırlık-Isınma}

Öğretmen, çember şeklindeki öğrencilere "Heykel” oyununu oynayacaklarını söyler. Oyunun kuralları gösterilerek anlatılır:

\section{Heykel Oyunu}

Öğrencilerden müziğin ritmine (Helena Paparizou, My Number One) uygun olarak mekânda yürümeleri istenir. Öğretmen müziği durdurduğu anda öğrencilerin kımıldamadan heykel gibi durmaları gerektiği söylenir. Eğer müzik durduktan sonra hareket eden olursa oyun dişında kalır. Oyun tek kişi kalana kadar devam eder.

Öğretmen, öğrencilerden sınıfın girişinde toplanmalarını ister... Öğretmen tarafından öğrencilere müzeyle ilgili bilgi verilir... Öğrencilere Kum Heykeli Müzesi’nin açılışında oldukları söylenir... Öğrencilere dünyaca ünlü kişiler oldukları söylenir... Ünlü kimliklerinden çıkmadan müzeyi gezmeleri istenir... Düşüncelerini, rolünü yaptıkları kişiliğe girerek anlatmaları istenir... Bir süre sonra mekanda 5-6 kişi ile karşılaşmaları, rollerinden çıkmadan konuşmaları istenir... Heykellerin altına boş bir kâğıt konur ve öğrencilerden o kâğıtlara heykel'in hangi çağa ait olabileceğini ve isminin ne olabileceğini kâğıtlara yazmaları istenir (Taş Devri, İlk Çağ vb.)...

Öğretmen, öğrencilerden heykel resimlerinden bir tanesini seçip bedenlerini kullanarak heykel ile göstermelerini ister... Bütün öğrenciler heykel olduktan sonra öğretmen, öğrencilere seçtikleri heykel eğer ses çıkarmış olsaydı nasıl bir ses çıkarırdı?, der... Öğretmen, aralarda dolaşarak “heykel”lerin omzuna dokunur...

Öğretmen, öğrencilerden heykellere ses ile birlikte hareket katmalarını ister... Bir süre sonra öğrencilerden toplanmaları ve çember şeklinde oturmaları istenir...

\section{Ara Değerlendirme}

1. Kum Heykeli Müzesi'nde kimlerle karşılaştınız?

2. Karşılaştığınız kişilerle neler konuştunuz?

\section{Canlandirma}

Öğrencilerden bu müzedeki heykellerden hangisini çok sevdilerse onun önünde durmaları istenir... Aynı heykel resimlerini seçenlerin grup olmaları istenir... 5 grup oluşturulur... Gruplardan bu heykellerle bir öykü yazmaları ve bunu canlandırmaları istenir (hazırlık süresinin 10 dakika olduğu söylenir)... Canlandırmalar izlenir... 


\section{Değerlendirme}

Öğretmenin önceden hazırlamış olduğu seramik çamuru her gruba dağıtılır... Gruplara, dünyanın önde gelen kum heykel sanatçıları olduğu söylenir... Gruplardan, çocukların ilgisini çekecek bir heykel sergisi oluşturmaları istenir... Gruplardan heykellerini bitirdikten sonra bunu sergilemeleri istenir (gruplara hazırlanmaları için 20 dakika süre verilir)... Gruplar çalışmalarını tamamladıktan sonra birlikte heykel sergisi oluşturmaları istenir...

\section{Oturum}

Ders: Sanat Etkinlikleri Dersi

Sinıf: 5-C

Süre: $40+40+40+40+40+40=240$ dakika (ders saati)

Tarih: 20.05 .2007

\section{Öğrenme Alanı: Müze Kültürü}

Tema: Tarihte Yaşam Kültürü

Kazanım: 1.Müzede geçmişteki yaşam kültürlerini gösteren eserleri tanır.

2.Geçmiş ve günümüzdeki yaşam kültürüne ait farklı ve benzer nesneleri karşılaştırır.

3.Geçmiş ve günümüze ait yaşam kültürünü müzede ya da sınıfta canlandırır.

Yöntem ve Teknikler: Yaratıcı drama, rol oynama, doğaçlama,

Araç-Gereç: 5 adet resim kâğıdı, 5 adet A4 kâğıdı, kurşun kalem ve boya kalemleri.

\section{Hazırlık-Isınma:}

Öğretmen, çember şeklindeki öğrencilere "İnci Hanım” oyununu oynayacaklarını söyler. Oyunun kuralları gösterilerek anlatılır:

Öğrencilerin çember olması istenir. Bir kişi ebe olur ve çemberin etrafinda dolaşmaya başlar. Dokunduğu kişi, çemberde ebenin gittiği yönün tersine doğru koşmaya başlar. Karşılaştıklarında, dururlar "Merhaba İnci Hanım! Nasılsınız İnci Hanım? İyi Günler İnci Hanım!” diyerek tokalaşırlar ve boş olan yeri kapmaya çalışırlar. Açıkta kalan yeni ebe olur.

Müze girişinde öğrencilerden eş olmaları istenir... Öğretmen, eşlerin el ele tutuşmasını ve eşlerden birisinin gözlerini kapatmasını ister... Eşlerini bu mekânda gezdirmeleri ve eşlerine müzede gördüklerini anlatmaları istenir... Eşlerinin can güvenliğinden sorumlu oldukları söylenir (bir süre geçtikten sonra)... Öğretmen, öğrencilerden bulundukları yerde durmalarını ve rolleri değiştirmelerini ister (gözü kapalı olanların açması, açık olanlar kapatması istenir)... Bir süre geçtikten sonra eşlerini müzenin girişine getirmeleri istenir... Öğretmen, öğrencilerden, gözlerinin açık olarak müzeyi iki'li olarak gezmeye devam etmelerini ister...

\section{Canlandirma}

Öğretmen, öğrencilerin, müzeyi gezdikten sonra müzenin bahçesinde çember olmalarını ister... 1'den 4'e kadar saymaları istenir... 4 tane grup oluşturulur... Gruplara kâğıt ve kalem verilir...

1.gruba "Öğretmen" oldukları söylenir. Müzede en çok beğendikleri ve en çok sevdikleri nesneyi grup olarak belirlemeleri ve adlarını yazmaları istenir... Bu nesneleri seçmelerinin nedenlerini yazmaları istenir...

2.gruba "Sanatçı" oldukları söylenir... Müzedeki hangi nesnenin yapımınının çok zaman aldığını belirlemeleri ve adını yazmaları istenir... Bu nesnenin neden diğerlerinden daha fazla zaman aldığını yazmaları istenir...

3.gruba "Sanat Eleştirmeni” oldukları söylenir... Müzedeki en iyi parçayı seçmeleri ve adını yazmaları istenir... Bu parçayı neden seçtiklerine ilişkin nedenlerini yazmaları istenir...

4.gruba "İş adamı" oldukları söylenir... Müzedeki nesnelerden en çok para edeceğini düşündükleri parçayı seçmeleri ve adını yazmaları istenir... Bu nesnenin neden en çok para ettiğini nedenleri ile yazmaları istenir (gruplara hazırlanmaları için 15 dakika süre verilir)...

\section{Ara Değerlendirme}


Öğretmen, gruplara mesleklerinin bakış açısıyla müzede hangi nesneleri ve bunları neden seçtiklerini sorar?

Öğretmen, gruplardan seçtikleri nesnenin yıllarca nasıl yaşadığı ve sonunda bu müzeye nasıl geldiği konusunda bir öykü yazmalarını ve bunu canlandırmalarını ister... Gruplara hazırlanmaları için 20 dakika süre verilir...

Müzenin istedikleri bir köşesinde bunları canlandırmaları istenir... Grupların canlandırmaları izlenir...

Canlandırmalar izlendikten sonra 1.gruptan (Şair) Müzeyi tanıtan şiir yazmalar istenir... 2.gruptan Müzeyi tanıtan reklâm afişi hazırlamaları istenir... 3.gruptan müzeyle ilgili bir gazete manşeti hazırlamaları istenir...4.gruptan (Müzik grubu) Midas'ın Tümülüsü’nün ziyaret edileceğini bunun için çevredeki nesneleri de kullanarak bir müzik hazırlamaları istenir.

\section{Değerlendirme}

Öğretmen, öğrencilerin müzede yaşadıklarıyla ilgili duygu ve düşüncelerini anlatan mektup yazmalarını ister (mektubu kime isterlerse yazabilecekleri söylenir).

\section{EK 2: Öğrenci değerlendirme formu}

Öğrencinin

Ad1 ve Soyadı: M. Y1lmaz

\section{Yaratıcı Drama Yöntemine İlişkin Öğrenci Değerlendirme Formu}

Sevgili Öğrenciler ;

$\mathrm{Bu}$ form sizinle birlikte yaratıcı drama yöntemi ile işlemiş olduğumuz Sanat Etkinlikleri Dersi "Tarihte Yaşam Kültürü” temasında uygulanan yönteme ilişkin duygu ve düşüncelerinizi almak amaciyla hazırlanmıştır. Vereceğiniz yanıtlar notla değerlendirilmeyecektir. Bu nedenle açık ve samimi cevap verebilirsiniz. Katkılarınız için teşekkür ederim.

\section{1. “Tarihte Yaşam Kültürü” temasının yaratıcı drama yöntemi ile işlenmesi sizi mutlu etti mi? Neden?}

Beni çok mutlu etti. Çünkü eski tarihimizle ilgili çok şey merak ediyordum. Şimdi eski tarihteki yaşam kültürümüz ile bizim kültürümüzle benzerliğinin olup olmadığını yaşayarak öğrendim.

\section{Müzedeki çalışmalar sırasında hangi duyguları yaşadınız?}

Ben daha önce de müzelere gitmiştim ama sıkllmıştım. Öğretmenimle müzelere gittiğimizde hiç sıkılmadım. Çünkü hem oyunlar oynadık hem de canlandırmalar yaptık. Çok mutlu oldum.

\section{Yaratıcı drama yöntemiyle daha iyi öğrendiğinizi düşünüyor musunuz?}

Yaratıcı drama yöntemiyle daha iyi öğrendiğimi düşünüyorum. Çünkü drama yapınca öğrendiklerim aklımda daha iyi kallyor.

\section{Diğer derslerde de yaratıcı drama yönteminin uygulanmasını ister misiniz?}

Yaratıcı Drama'nın diğer derslerde de uygulanmasını isterim. Yaratıcı dramayla ders işlemek rahatlamamı sağllyor ve daha kolay öğreniyorum.

\section{EK 3: Etkinlik değerlendirme formuna bir örnek}

\section{Etkinlik Değerlendirme Formu}

Müzenin Adı: Etnografya Müzesi

Öğrencinin

Ad1-Soyad1: R. İman

Açıklama: Aşağıdaki form katıldığınız etkinliği değerlendirmeniz amacıyla hazırlanmıştır.

1. Bu etkinlikte (çok heyecanllydım. İlk defa böyle bir yere gittiğim için mutluluk) hissettim.

2. Bu etkinliğin en hoşlandığım yerleri (Kına gecesinin bulunduğu yeri, sünnet odasının ve damat tıraşının yapıldı̆̆ heykelleri çok sevdim). 
3. Bu etkinliğin (drama yöntemiyle işlediğimiz yerleri, oyun oynadığımız, canlandırma yaptı̆̆ımız ve müzeyi gezdiğimiz) yerlerinde yaratıcılı̆̆ımı kullandım.

4. Bu müzeyi arkadaşlarıma öneririm. Çünkü: Kına gecesi heykeli, sünnet odası ve damat tıraşı heykelleri güzeldi. Ayrıca canlandırmalar çok güzeldi.

5. Bu müzeyi arkadaşlarıma önermem. Çünkü: ...

EK 4: Öğrenci mektuplarına bir örnek

\section{Sevgili ăgabeyciğim ve babacı̆̆ım;}

Bu pazar çok güzel zaman geçirdim. Drama öğretmenimiz bizi Gordion'a götürdü. Otobüsten indikten sonra önce arkadaşlarımızla güzel bir kahvaltı yaptık. Daha sonra müzenin bahçesinde güzel bir oyun oynadık. Sonra ikili eş olduk ve müzeyi birlikte gezdik. Müzede eski insanların yaptıkları paraları, tabakları, bardakları ve mühürleri gördüm. Arkadaşlarımla grup oluşturduk ve öğretmenimiz bizden en sevdiğimiz nesneyi seçmemizi istedi. Biz müzede bulunan iskeleti seçtik ve bir öykü yazıp onu canlandırdık. Öğle yemeğimizi yedikten sonra Kral Midas'ın mezarını gezdik. Orasını çok beğendim. Mezardaki kocaman kütükleri üst üste nasıl koyduklarını ve zorlanmış olabileceklerini düşündüm. Mezarın üstünü toprakla kapatmışlar. Burası kocaman bir tepe olmuş. Bu pazar hem ĕ̆lendik hem de çok şey öğrendik. Bizi buraya getiren bütün öğretmenlerime teşekkür ediyorum. Birazdan yola çıkacă̆ız. Akşama görüşürüz. Sevgilerimle...

F. Şahin 


\title{
Summary \\ The Evaluation of the Creative Drama Method within the Art Facilities Course in the Primary Schools in terms of Students Satisfaction
}

\author{
Murtaza AYKAÇ.
}

\section{The Significance of the Study}

This study was carried out in accordance with the implementation of the theme (via the creative drama teaching method) 'Life Culture Throughout the History' within the curriculum of the course 'Art Facilities' given in the education year 2006-2007. The study has significance for two reasons. The former is due to the fact that it is one of the first studies done in order to evaluate the Art Facilities Course. The latter is a consequence of the fact that it is a student- centered course depending upon students' lives.

With this point of view, Art Facilities Course, which gives importance to active method such as theatre and drama and encompasses various sorts of art just as portrait, sculpture and music, is supposed to have an importance in the primary schools as a consequence of using not only the classroom but also the different educational settings as museums and art galleries. This course is planned focusing on how to proceed students' point of view towards works of art and develop their creativity and imagination. It also could be converted to an efficient learning process via creative drama method. To determine the quality of student satisfaction and motivation and to provide effective learning process are both crucial to enhance art facilities.

\section{The Objective of the Study}

The aim of the study is to evaluate the course of Art Facilities at the $5^{\text {th }}$ grade in primary schools in terms of the students' pleasure using creative drama method within the scope of learning the museum culture in the theme of 'Culture of Life throughout History'.

\section{Participants}

The study was carried out with the participation of the students studying at 5/C class of Şehit Mehmet Altanlar Primary School, in the city Ankara, in the county Keçiören and in the education year 20062007. The student's ages were 12-13; 13 of them were girls, and 14 were boys- totally 27 students participated in the study. 


\section{The Methods and Techniques Used in the Study}

In the study some certain techniques used are; improvisation, role playing, still image, photographs moment.

\section{The Data Gathering Tools of the Study}

In the study "student evaluation form" including 4 open ended questions and "facility evaluation form" including 5 open ended questions were prepared and used as means of data gathering tools. Beside them, the letters describing how students felt and thought in Gordion Museum were also used as means of data gathering tool. With the aim of determining students' pleasure, some questions were asked in the student evaluation form: "Were you happy during the learning process? Why? How did you feel during the studies in the museum? Do you think that you learn better with the creative drama method? Why? Would you like to be used creative drama method in other lessons? Why?" Students were supposed to clarify their feelings by semi constructing the facility evaluation form like these expressions: "I felt........in this activity, the best parts that I liked of this activity ......, I recommend this museum to my friends because......" The scale was formed by making some necessary corrections depending on Turkish, Measurement and Evaluation and Curriculum Development experts' opinions and suggestions about the data gathering tools that were prepared as it was mentioned above. The scales prepared by this way were applied to the twenty $4^{\text {th }}$ grade students in Türkkent Primary School with the aim of experimentation. As a result of the implementations, the scales used as means of the data gathering tools after It had been understood that the expressions in the scales were comprehensible and they were appropriate in terms of the aims of the research. Students' opinions and thoughts obtained from these measuring tools were interpreted by being grouped and the results were summarized below.

\section{Conclusions and Suggestions}

Students indicated that they did the activities sharing everything in the group works using creative drama, animating and playing games in creative drama made the lessons enjoyable and fluent and having the lesson with the creative drama method made them happy. As the students also learned whether the life culture in the history is related to the culture today or not by living it, doing improvisations, animating, preparing posters and painting, they expressed that they learned better the theme of the life culture in the history with the creative drama and what they learned became permanent.

Considering the results of the implementations generally, it could be supposed that the classroom setting turning into the museum from a traditional classroom setting and the museums where is a kind of learning center, the learning process that supplies students' participation democratically made an 
important effect in terms of the permanence of learning and students' pleasure with the researcher's observations and the students' opinions. From this point of view, schools could turn into the center that the students are anxious about and interested in it and they feel happiness and excitement when they learn in it rather than a place that the students run away immediately when the bell rings. It is also the same for the museums; museums and exhibitions could turn into an effective education settings for students that the communities share their cultural, artistic and historical productions and live the cultural features and historical values using effective methods like creative drama rather than a place that only includes some objects and can be walked around in a shot time. In the light of these results, the suggestions were written below from the point of being effective of creative drama method and the functionality of museum education. Museums should be rearranged to be used more functionally not only physically but also visually. Teachers and students should be able to get more easily into the museums and the bureaucratic matters and procedures should be reduced. 
